\title{
A Comparative Performance Analysis of ROUTE REDISTRIBUTION AMONG THREE Different Routing PRotocols BASED ON OPNET SIMULATION
}

\author{
Zeyad Mohammad $^{1}$, Ahmad Abusukhon $^{2}$ and Marzooq A. Al-Maitah ${ }^{3}$ \\ ${ }^{1,3}$ Department of Computer Network, \\ Al-Zaytoonah University of Jordan, Amman, Jordan \\ ${ }^{2}$ Department of Computer Science, \\ Al-Zaytoonah University of Jordan, Amman, Jordan
}

\begin{abstract}
In an enterprise network, it is normal to use multiple dynamic routing protocols for forwarding packets. Therefore, the route redistribution is an important issue in an enterprise network that has been configured by multiple different routing protocols in its routers. In this study, we analyse the performance of the combination of three routing protocols in each scenario and make a comparison among our scenarios. We have used the OPNET 17.5 simulator to create the three scenarios in this paper by selecting three different routing protocols from the distance vector and link state routing protocols in each scenario. In the first scenario, the network routers are configured from EIGRP, IGRP, and IS-IS that is named EIGRP_IGRP_ISIS in our simulation. The OSPF_IGRP_ISIS scenario is a mixed from EIGRP, IGRP, and IS-IS protocols that is the second scenario. The third scenario is OSPF_IGRP_EIGRP that is the route redistribution among OSPF, IGRP, and IS-IS protocols. The simulation results showed that the performance of the EIGRP_IGRP_ISIS scenario is better than the other scenarios in terms of network convergence time, throughput, video packet delay variation, and FTP download response time. In contrast, the OSPF_IGRP_ISIS has less voice packet delay variation, video conferencing and voice packet end to end delays, and queuing delay as compared with the two other scenarios. On the other hand, the performance of the OSPF_IGRP_EIGRP scenario has better FTP upload response time, and voice jitter.
\end{abstract}

\section{KEYWORDS}

Route Redistribution, EIGRP, IGRP, IS-IS, OSPF

\section{INTRODUCTION}

The advent of the large networks in $21^{\text {st }}$ century that have affected our daily lives prominently, where the large network might operate multiple different routing protocols in its infrastructure in order to be connected, therefore; the route redistribution becomes an important issue in its routers configuration. The route redistribution is a fundamental process in the routing protocol for a large network that uses multiple diverse routing protocols. A Routing is a basic process for choosing the shortest path from multiple paths in order to forward a packet from source to destination nodes at a minimum cost. The routing protocols can be classified into interior and exterior gateway protocols. Border Gateway Protocol (BGP) is an exterior gateway protocol. BGP is used to distribute routing information among autonomous system (AS) on the internetwork that is a distance vector routing protocol. An interior gateway protocol is used to distribute routing information between gateways within an AS. It is classified into distance vector 
International Journal of Computer Networks \& Communications (IJCNC) Vol.9, No.2, March 2017

and link state routing protocols. A distance vector algorithm constructs a vector that contains costs to all other nodes and advertises a vector to its neighbours whereas an each node in a link state algorithm advertises the state of the link to its neighbours and the cost of an each link. A distance vector routing protocol is a hop count metrics and the next hop presents a direction. It is based on Bellman Ford algorithm to compute the optimal path. Routing Information Protocol (RIP) is a distance vector routing protocol that measures its metrics by counting the number of hops between source and destination nodes. RIP selects the minimum number of hops for reaching a destination. RIP allows a maximum hop count of 15 hops in a path, in the case of the hop count exceeding 15 hops for reaching a destination network, it is considered unreachable network. RIP updates its full routing table with its closest neighbours every 30 seconds, and the administrative distance in RIP is 120 [1].

Interior Gateway Routing Protocol (IGRP) is based on a distance vector routing protocol, and IGRP handles maximum hop count up to 255 hops, where 100 is a default hop count in IGRP. IGRP sends a full routing table every 90 second, and the hold down timer of IGRP is 280 seconds. The administrative distance of IGRP is 100, and IGRP uses bandwidth, delay, reliability, load, and maximum transmission unit (MTU) in its metric, where bandwidth and delay are default metric in IGRP [2].

Enhanced Interior Gateway Routing Protocol (EIGRP) is an enhancement of IGRP that uses diffusion update algorithm instead of hop count compared with IGRP to select the optimal path between source and destination nodes. The administrative distance used by EIGRP is 170 for external routes outside the local AS and 90 for routes originating within the local AS. EIGRP is a successor to the IGRP consequently they are compatible in their operation, where the used metric in one protocol can be translated into the metrics of the other protocol. EIGRP sends updates only when changes made, and the only changes part are transmitted, not the entire routing table. This will cause rapid convergence and reduce the load of routing protocol [3].

A link state routing protocol is based on Dijkstra's algorithm to find the optimal path between source and destination nodes. Open Shortest Path First (OSPF) and Intermediate System to Intermediate System (IS-IS) are a link state routing protocol. OSPF is standardized by the Internet Engineering Task Force (IETF) as interior gateway Protocol. The OSPF is designed to support large networks efficiently. OSPF protocol is used to find the optimal for the information to reach a particular destination. OSPF uses cost as its metric, which is computed based on the bandwidth of the link. OSPF has no hop-count limit and its administrative distance is 110, it supports classless protocol. OSPF advertises the status of directly connected links using Link-State Advertisements (LSAs). OSPF sends updates (LSAs) only the part that has changed and only when a change has taken place. LSAs are additionally refreshed every 30 minutes $[4,5]$.

The IS-IS is standardized link-state routing protocol that is an interior gateway protocol for the Internet.IS-IS is designed to move information efficiently within a computer network. It exchanges topology information with their nearest neighbours, and distributes IP routing information throughout a single AS in an IP network. IS-IS executes the Shortest Path First (SPF) algorithm on the information in the link-state database in order to obtain the optimal path to each destination on the network, thereafter stores the pairs of the destination and next-hop as a result of computing the SPF algorithm into IS-IS routing database. IS-IS executes directly on the data link layer, Because it was developed as part of the OSI network protocols and not part of TCP/IP, IS-IS doesn't use IP addresses. IS-IS addresses are called NETs, or network entity titles [6, 7]. The enterprise networks are created from multiple routers that are running different routing protocols in order to distribute their route information; we need to configure the route redistribution into routers in the network. The route redistribution exchanges the route information between two diverse routing protocols that requires the common border router. The 
International Journal of Computer Networks \& Communications (IJCNC) Vol.9, No.2, March 2017

common border router executes routing processes in both routing protocols. The border router may be configured to redistribute routes from one routing protocol to the other, and vice versa. The route redistribution is needed in case of company mergers, multiple departments managed by multiple network administrators, multi-vendor environment, and split of two independent routing domains $[8,9]$. The route redistribution has two main objectives. The first objective is to exchange route information between diverse routing protocols for connectivity purposes. The second objective is the alternative links in case of a network failure, the routing protocol should be able to support alternate forwarding paths to each other. In addition, most of existing solutions apply to scenarios with only two routing protocols, but large operational networks usually include more than two routing protocols in the network [10]. The route redistribution might face some issues during running multiple diverse routing protocols due to an each routing protocol has its characteristics such as metrics, administrative distance, convergence rate, classful and classless capabilities. Each routing protocol uses different metrics in order to compute the shortest path. IGRP and EIGRP have the same metrics, but they are different in the administrative distance, and a network convergence time [11]. OSPF metric is based on bandwidth, but IS-IS metric is based on cost of link utilization, delay, expense and error, where Cisco implementation uses cost only $[12,13]$. Each routing protocol has a different network convergence time such as EIGRP convergence time is faster than IGRP. A network convergence is the status of a set of routers that have the same topological information about the network of which operating. When a link fails or recovers thereafter a set of routers needs to run their routing protocols in order to advertise their routing information with neighbours to form the same topological information about their network.

The most researchers have been focused on the comparison and analysis of the performance of dynamic routing protocols and the route redistribution between two different routing protocols. They did not consider the comparison and analysis of the performance of the route redistribution among three different routing protocols in various scenarios on the same network $[14,15,16]$. In this study, we analyse and compare the performance of the route redistribution among three different routing protocols that are configured on the same network. We have created three scenarios on the same network topology, where the first scenario is a combination of EIGRP, IGRP, and IS-IS, the second scenario is a mixed of OSPF, IGRP, and IS-IS, and the third scenario is a combination of OSPF, IGRP, and EIGRP.

The main goal of this study is to analyse and compare the performance of the three scenarios in terms of convergence duration time, queuing delay, throughput, voice jitter, voice and video conferencing packet delay variations, voice and video conferencing packet end to end delays, FTP upload response time, and FTP download response time.

Our paper is organized as follows: In section 2, we review briefly about the performance analysis of dynamic routing protocols and the route redistribution of different routing protocols. We describe the three scenarios of the proposed network that have been created by the OPNET 17.5 simulator in section 3. In section 4, we analyse and compare the performance of three scenarios. We present our conclusions in section 5.

\section{RELATED STUDY}

Farhangi et al. [14] analysed and compared the performance of the route redistribution between two diverse dynamic routing protocols by using OPNET. Their simulation results showed that the performance of the mixed three protocols EIGRP, OSPF and IS-IS in terms of end to end delay, packet delay variation, voice Jitter and link throughput outperforms the other two combination from the same three routing protocols. Dey et al. [15] investigated a comparative performance analysis of dynamic routing protocols. They showed how to transmit data among 
International Journal of Computer Networks \& Communications (IJCNC) Vol.9, No.2, March 2017

different networks that are used different dynamic IP routing protocols based on route redistribution systems in Cisco packet tracer simulator. Mukmin et al. [16] presented a comparative performance analysis of route redistribution on dynamic routing protocol by using Graphical Network Simulator (GNS3) in their simulation. Their simulation results showed that the route redistribution EIGRP into IS-IS has less delay and packet loss compared with the route redistribution EIGRP into OSPF but in terms of throughput the combination of EIGRP and OSPF has better result. Jayaprakash and Saroja [17] analysed the performance of RIP, OSPF, IGRP and EIGRP routing protocols. They concluded that EIGRP is the fastest router convergence time in their simulation. Hamza and Mohamed [18] presented the performance comparison between distance vector and link state. They showed in the simulation that OSPF has a better performance than RIP in terms of average throughput and packet delay in different network sizes. Nigam et al. [19] presented theoretical analysis of RIP, EIGRP and OSPF routing protocols. Nazumudeen and Mahendran [20] analysed the performance of dynamic routing protocols by using Cisco packet tracer simulator. They concluded that EIGRP has better performance among dynamic routing protocols. Ali el al. [21] presented a comparative study of IGP and EGP routing protocols. They evaluated the performance of load balancing and redundancy via different autonomous system. They simulated and analysed the combination of EIGRP and OSPF in large network and they obtained that combination is the best for large network but the combination of EIGRP and RIPv2 is more suitable for small size network. Archana [22] simulated and analysed of EIGRP, RIP and OSPF in wired local area network by using Cisco Packet Tracer. Sendra et al. [23] presented a survey of main interior gateway IP routing protocols in details. They tested a performance of EIGRP, RIPv1, RIPv2 and OSPF routing protocols. Verma and Bharddwaj [24] reviewed RIP and OSPF routing protocol and addressed the development in both protocols. They found that OSPF outperforms RIP in terms of throughput and packet delay. Vetriselvan et al. [25] surveyed the performance evaluation of dynamic routing protocols in terms of jitter, convergence time and end to end delay. Kumar et al. [26] implemented of experiment of the route redistribution between EIGRP and OSPF routing protocol in computer network by using GNS3 emulator. Lakshmi and Rao [27] studied the designing issues of protocols at the network layer and reviewed the existing routing protocols for wired and wireless networks. Vasudha et al. [28] presented the modelling and simulation of WAN based on the OPNET to investigate the performance of integration of RIP with OSPF. They studied behaviour of FTP traffic, wireless load and delays. Abdulkadhim [29] concluded in his study that the convergence time of OSPF is faster than RIP. He simulated RIP, OSPF and EIGRP on the OPNET and He noticed from his analysis of the simulation that EIGRP has the minimum impact on the network. Asher [30] discussed the routing IP protocol and summarized the features of RIP, OSPF, IS-IS, IGRP, EIGRP and BGP routing protocols. Rathi and Singh [31] described the distance vector and link state routing protocols in details. They simulated the distance vector and link state routing protocols with both IPv4 and IPv6 on GNS3 emulator. Their simulation showed that EIGRP outperforms the distance vector protocols, and OSPF is the best link state routing protocols. Sandhu et al. [32] simulated RIP, EIGRP, IGRP, and OSPF routing protocols on the OPNET simulator and they observed two factors: throughput and queuing delay on both ends transmitter and receiver. Their conclusion was the throughput, utilization, and delay of EIGRP outperforms other routing protocols in experiment. Grang et al. [33] discussed OSPF in details and compared it with other interior routing protocols. Shubhi and Shukla [34] presented the theoretical and practical analysis of the distance vector and link state routing protocols. They simulated the distance vector and link state routing protocols in MATLAB. The result of simulation showed that distance vector routing protocols have periodic updates, low utilization of CPU and memory and high simplicity compared with link state routing protocols. Sonam et al. [35] described the analysis of ISIS,IGRP, and RIP dynamic routing protocols working on FTP, remote login and videoconferencing applications based on increasing number of packets per second sent. They used the OPNENT simulator to evaluate the dynamic routing protocols and the results of simulation showed that IS-IS has best performance than IGRP and RIP in case of increasing 
International Journal of Computer Networks \& Communications (IJCNC) Vol.9, No.2, March 2017

number of packets in the given scenario. Jelodar and Nikravesh [36] assessed RIPv1 and OSPFv2 routing protocols in terms of convergence and sending protocols traffic by using the OPNET simulator. They observed from the simulation that OSPFv2 is more an efficient than RIPv1 protocols. Prasad et al. [37] studied and analysed RIP, OSPF and EIGRP routing protocols in terms of bandwidth is used during convergence. IQBAL and KHAN [38] described RIP, OSPF and EIGRP routing IP protocols in details. They simulated three routing protocols for supporting voice, video and HTTP traffic on the OPNET. The simulation showed that EIGRP performance was stable most of the time when there were flapping links and OSPF performance was improved when there were more flapping links in the network. Kumar et al. [39] analysed the performance of RIPv2 in Cisco packet tracer in terms of routing update, convergence time, invalid timer, hold timer and flush-out timer parameters. They optimized these parameters to improve quality of service and make RIP fast. Patel et al. [40] analysed the performance of OSPF and EIGRP routing protocols in terms of route summarization and route redistribution in GNS3. Syed \& Ambore [41] presented the comparative analysis in behaviour of RIP and OSPF in IPv4 and IPv6 using G.711 CODEC with riverbed modeller 17.5. Their simulation results showed that OSPFv3 has lesser a traffic sent than RIPng when a call is placed from one end to the other although OSPFv3 has more a traffic sent than OSPFv2 however OSPFv3 outperforms OSPFv2, RIPv2 and RIPng in terms of packet delay variation, moreover, RIPng has better results in terms of traffic dropped, end to end delay, and jitter. Wijaya [42] analysed the performance parameters of EIGRP and OSPF in IPv4 and IPv6 network by using the GNS3 and Cisco packet tracer simulators, and the simulation results showed that EIGRP is better than OSPF in terms of performance parameters. Gurupandi et al. [43] proposed a new form interconnection to overcome the limitations of route election and route redistribution, permit the configuration of a resilient and efficient routing system. They demonstrated a simulation of the route redistribution among RIP, OSPF, and EIGRP on Cisco packet tracer.

\section{The Proposed NeTWORK}

We have used the OPNET 17.5 to create the proposed network as shown in Figure 1. In the proposed network, we have 11 routers that are Ethernet4_slip8_gtwy, and all the routers are connected together with point to point (PPP) by using Digital Signal 3 (DS3) link model, where DS3 link speed is 44.736 Mbps, whereas the R4, R5, R6, and R7 routers are the border routers which are used for exchanging different route information in the network, in addition, we have SW1 and SW2 switches that are Ethernet16_switch node model and are connected with the two end points in the network by a 100BaseT link in which operating at 100 Mbps. Figure 1 shows three Ethernet servers that are connected with SW1 switch via an Ethernet connection, where a VoiceSerever is used to provide a voice service, a VideoServer is used to support a video conferencing, and an FTPServer is used to provide a File Transfer Protocol (FTP) service. Furthermore, our proposed network consists of an Ethernet local area network (LAN) in which is connected with a SW2 switch via a 100BaseT link. A LAN is configured to support 25 users for using FTP with a low load. We have four Ethernet workstations in the proposed network that are used to support the real time applications, where the two workstations have been configured for a voice service with a low quality and silence suppressed, and the other two have been configured for a video conferencing service with a low resolution video. . In order to analyse the network convergence duration time of the proposed network, we applied a Failure Recovery node that is the simulator of fails in nodes or links of the real communication networks. The links between the following nodes: R11 $\rightarrow \mathrm{R} 8, \mathrm{R} 6 \rightarrow \mathrm{R} 4$, and $\mathrm{R} 4 \rightarrow 2$ are an important communication link in the proposed network due to the path between source and destination nodes is the shortest path $(\mathrm{R} 11 \rightarrow \mathrm{R} 8 \rightarrow \mathrm{R} 6 \rightarrow \mathrm{R} 4 \rightarrow \mathrm{R} 2 \rightarrow \mathrm{R} 1)$ as compared with the other path $(\mathrm{R} 11 \rightarrow \mathrm{R} 10 \rightarrow \mathrm{R} 9 \rightarrow \mathrm{R} 7 \rightarrow \mathrm{R} 5 \rightarrow \mathrm{R} 3 \rightarrow \mathrm{R} 1)$, so during our simulations, we apply failure recovery events as shown in Table 1, where the time is given in second. The total simulation time for each scenario is taken to be 600 seconds. 
Table 1. Link failure and recovery.

\begin{tabular}{|l|l|l|}
\hline Link & Fail & Recover \\
\hline $\mathrm{R} 11 \rightarrow \mathrm{R} 8$ & 180 & 240 \\
\hline $\mathrm{R} 6 \rightarrow \mathrm{R} 4$ & 300 & 360 \\
\hline $\mathrm{R} 4 \rightarrow \mathrm{R} 2$ & 420 & 480 \\
\hline
\end{tabular}

We have created the three scenarios that have been configured from a combination of three different routing protocols for each scenario on the same network. In section 3.1, we describe the configuration of the first scenario. We describe the configuration of the second scenario in section 3.2. In section 3.3, we discuss the configuration of the third scenario.

\subsection{The Route Redistribution among EIGRP, IGRP and IS-IS Routing Protocols}

The first scenario is the EIGRP_IGRP_ISIS that is a combination of EIGRP, IGRP, and IS-IS protocols. In Figure 1, we configured the redistribution parameters of IGRP protocol in the R4 and R5 border routers in order to redistribute the route information of IGRP protocol into EIGRP protocol. The redistribution parameters of EIGRP protocol have been configured to advertise its routing information into IGRP protocol. In the R6 and R7 boundary routers, we configured the redistribution parameters of IGRP protocol to distribute the route information of IGRP protocol into IS-IS protocol, and the redistribution parameters of IS-IS protocol are configured to redistribute the route information of IS-IS protocol into IGRP protocol as demonstrated in Figure 1.

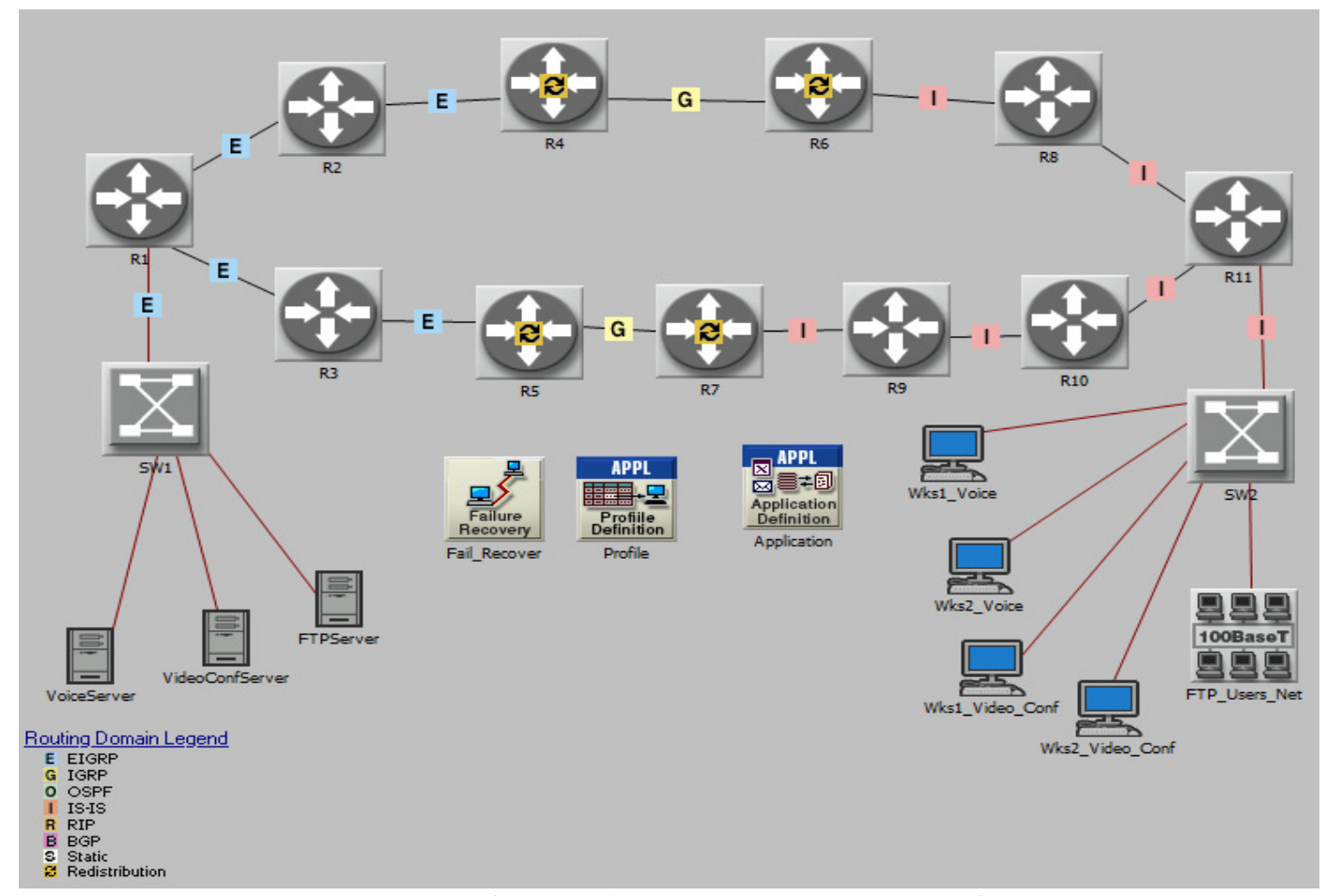

Figure 1. The EIGRP_IGRP_ISIS scenario 
International Journal of Computer Networks \& Communications (IJCNC) Vol.9, No.2, March 2017

\subsection{The Route Redistribution among OSPF, IGRP and IS-IS Routing Protocols}

The second scenario is the route redistribution among OSPF, IGRP, and IS-IS which is named the OSPF_IGRP_ISIS scenario. We configured the redistribution parameters of OSPF protocol in the R4 and R5 boundary routers to redistribute the route information of OSPF protocol into IGRP protocol, and vice versa as shown in Figure 2. In the R6 and R7 border routers, we configured the redistribution parameters of IGRP protocol to distribute the route information of IGRP protocol into IS-IS protocol, and the redistribution parameters of IS-IS protocol are configured to redistribute its route information into IGRP protocol as depicted in Figure 2.

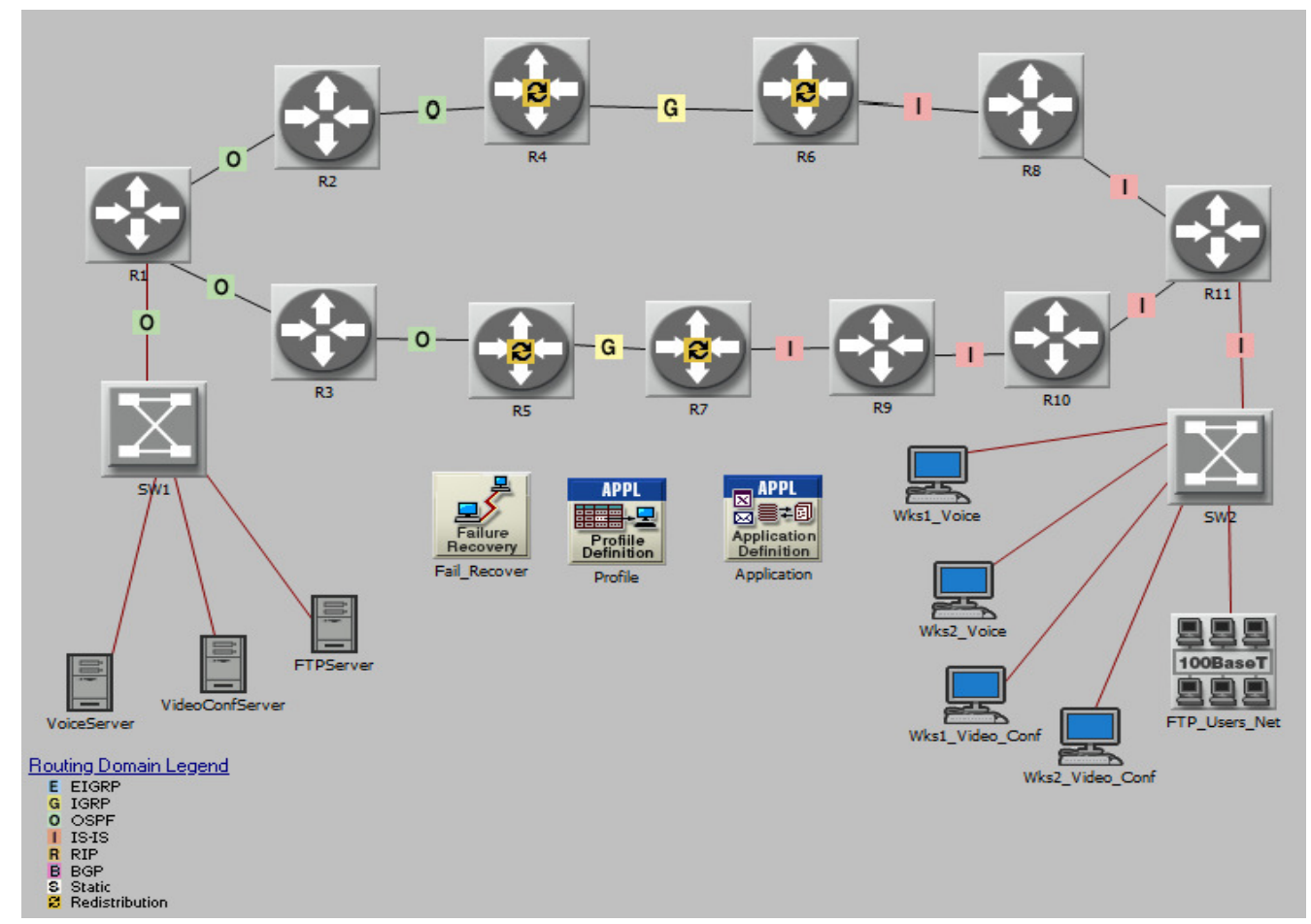

Figure 2. The OSPF_IGRP_ISIS scenario.

\subsection{The Route Redistribution among OSPF, IGRP and EIGRP Routing Protocols}

Figure 3 shows the third scenario that is the route redistribution among OSPF, IGRP, and EIGRP which is named the OSPF_IGRP_EIGRP scenario. In the R4 and R5 border routers, we configured the redistribution parameters of OSPF protocol to redistribute the route information of OSPF protocol into IGRP protocol, and vice versa as illustrated in Figure 3. We configured the redistribution parameters of IGRP protocol in the R6 and R7 border routers to distribute the route information of IGRP protocol into EIGRP protocol, and the redistribution parameters of EIGRP protocol are configured to advertise its route information into IGRP protocol as shown in Figure 3. 
International Journal of Computer Networks \& Communications (IJCNC) Vol.9, No.2, March 2017

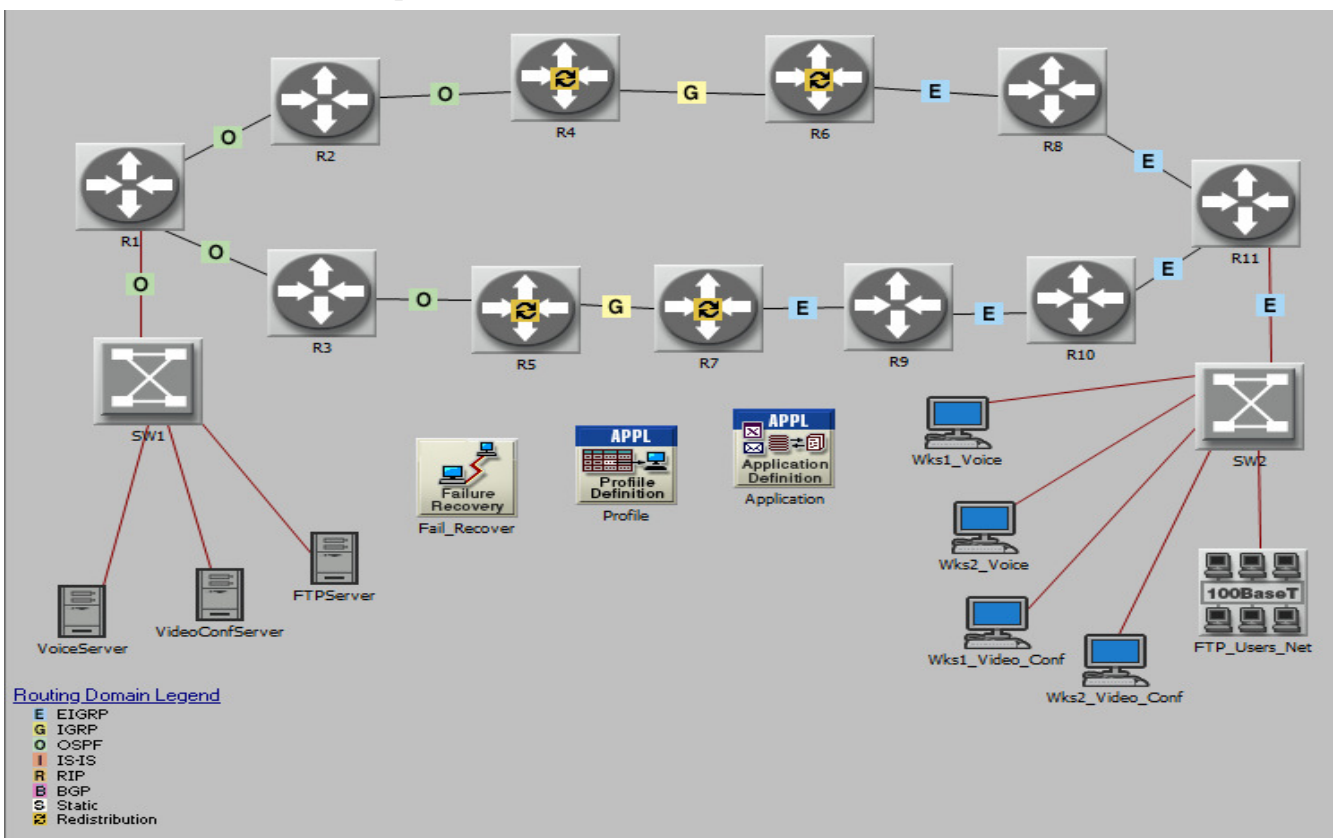

Figure 3. The OSPF_IGRP_EIGRP scenario.

\section{THE RESUltS ANALYSIS}

This section presents the results that obtained from the simulations of the three scenarios in this paper therefore, we analyse and compare the simulation results of the proposed scenarios then we make a decision about the scenarios in terms of the fitting applications for each scenario.

\subsection{Network Convergence Time}

We applied a Failure Recovery node as shown in Table 1 in order to analyse an average convergence duration time of the proposed network in this study, where a convergence duration time is how fast the convergence to reach a stable state in the network when a link in network failed or recovered.

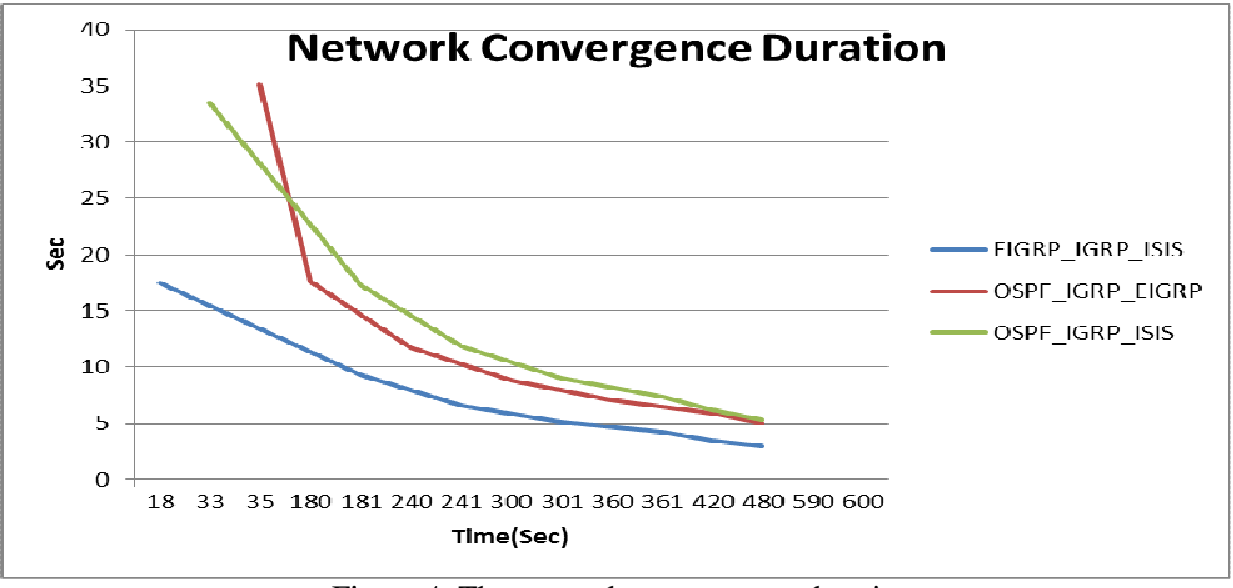

Figure 4. The network convergence duration. 
International Journal of Computer Networks \& Communications (IJCNC) Vol.9, No.2, March 2017

Figure 4 shows the convergence time of the EIGRP_IGRP_ISIS scenario that has a better performance than the other scenarios since it has less convergence time before failures to be occurred in the network and after network recovery among the other scenarios. Therefore, the convergence duration time in the route redistribution among three protocols EIGRP, IGRP, and IS-IS is the fastest one in network convergence time.

\subsection{Queuing Delay}

The queuing delay is the packet time to enter the transmitter channel queue until the last bit of the packet is transmitted. It is used to measure a delay of point to point therefore we have measured the queuing delay in the link between SW2 and R11. We can see from Figure 5 the OSPF_IGRP_EIGRP scenario that has less the queuing delay before failure occurrence in the link between R11 and R8 thereafter the OSPF_IGRP_ISIS scenario outperforms the other scenarios in terms of the queuing delay because the OSPF_IGRP_ISIS is a mixed from the two link state routing protocols and one distance vector routing protocol and at the beginning, the link state routing protocols need much time to converge the network due to build their topological database thereafter they need less time to converge the network compared with the distance vector routing protocols consequently they withstand multiple links failure occurred in the network. Therefore, The OSPF_IGRP_ISIS scenario is less the queuing delay than the other scenarios.

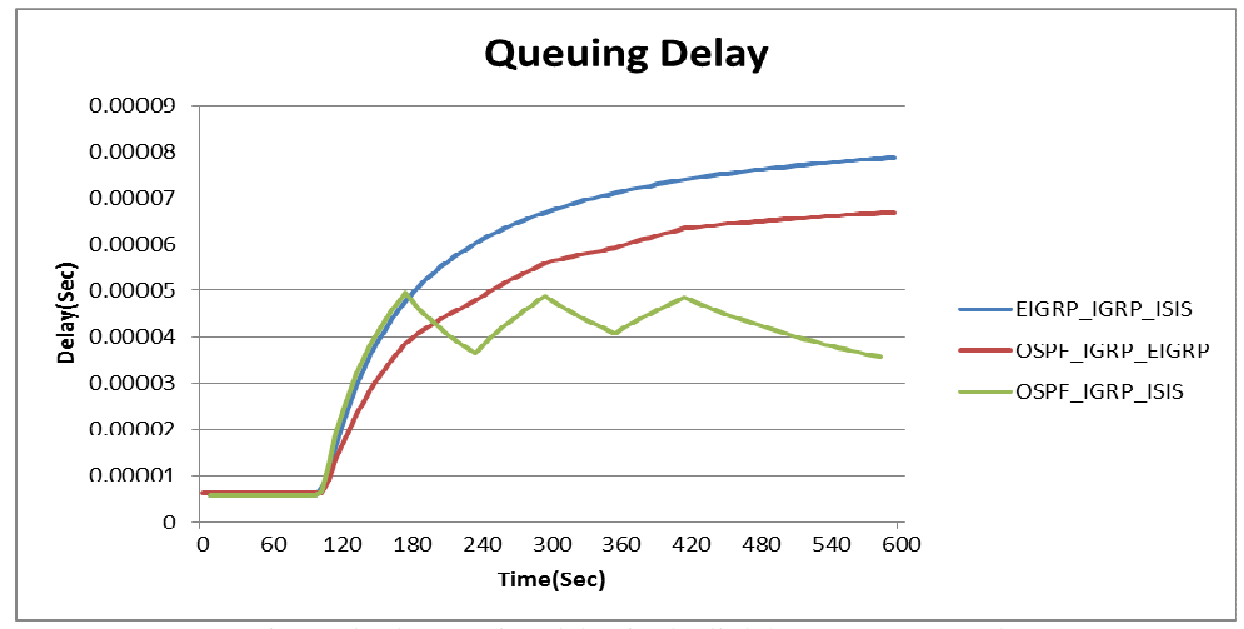

Figure 5. The queuing delay in the link between SW2 and R11.

\subsection{Throughput}

Figure 6 shows the throughput of the link between SW2 and R11, where the throughput is the average number of packets successfully received by the receiver channel per seconds. At the beginning the three scenarios have the same throughput, thereafter failure or recovery in links are occurred as shown in Table 1, we can see the OSPF_IGRP_EIGRP that has higher throughput than the others, but the EIGRP_IGRP_ISIS becomes better in terms of the throughput after three times of failure or recovery occurrences as shown in Figure 6, thus the throughput of the EIGRP_IGRP_ISIS scenario is better than the other scenarios, in case of multiple links failure or recovery are occurred in the network. 
International Journal of Computer Networks \& Communications (IJCNC) Vol.9, No.2, March 2017

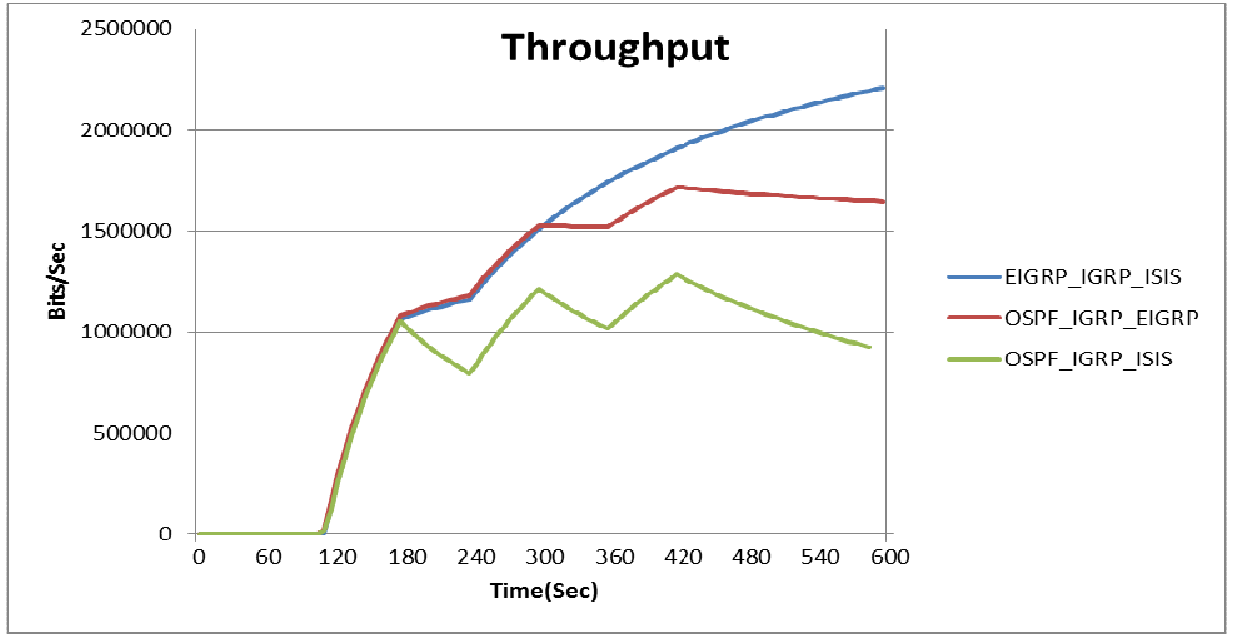

Figure 6. The throughput in the link between SW2 and R11.

\subsection{Video Conferencing Packet Delay Variation}

The EIGRP_IGRP_ISIS scenario is more stable than the others due to the difference between the values is closed to zero therefore it is the best performance in terms of the packet delay variation as shown in Figure 7.

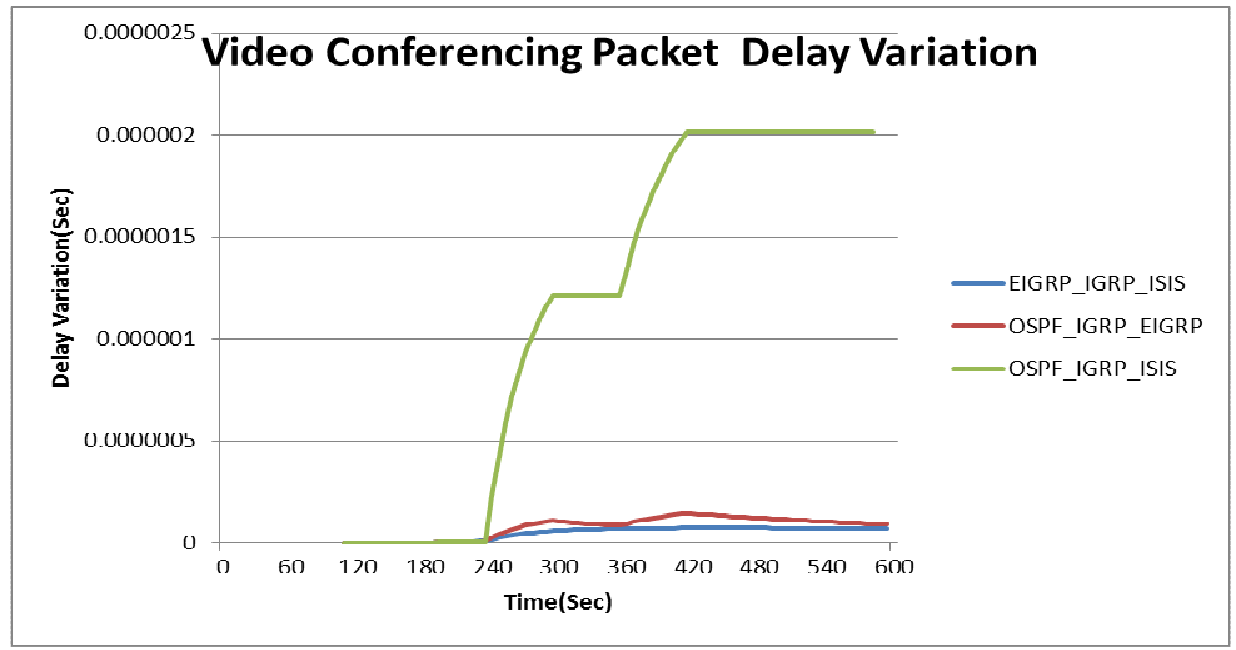

Figure 7. The video conferencing packet delay variation

\subsection{Video Conferencing Packet End to End Delay}

Figure 8 demonstrates the end to end delay of video conferencing service, where the end to end delay is the taken time to transmit a packet over the network from the sender to the receiver. As seen in Figure 8, the OSPF_IGRP_ISIS scenario has less packet end to end delay before failure or recovery in the links are occurred and after occurrence consequently it is better than the other scenarios in terms of the video conferencing end to end delay. We conclude from Figure 7 and Figure 8 that the EIGRP_IGRP_ISIS scenario is better slightly than the OSPF_IGRP_ISIS scenario for video conferencing service. 
International Journal of Computer Networks \& Communications (IJCNC) Vol.9, No.2, March 2017

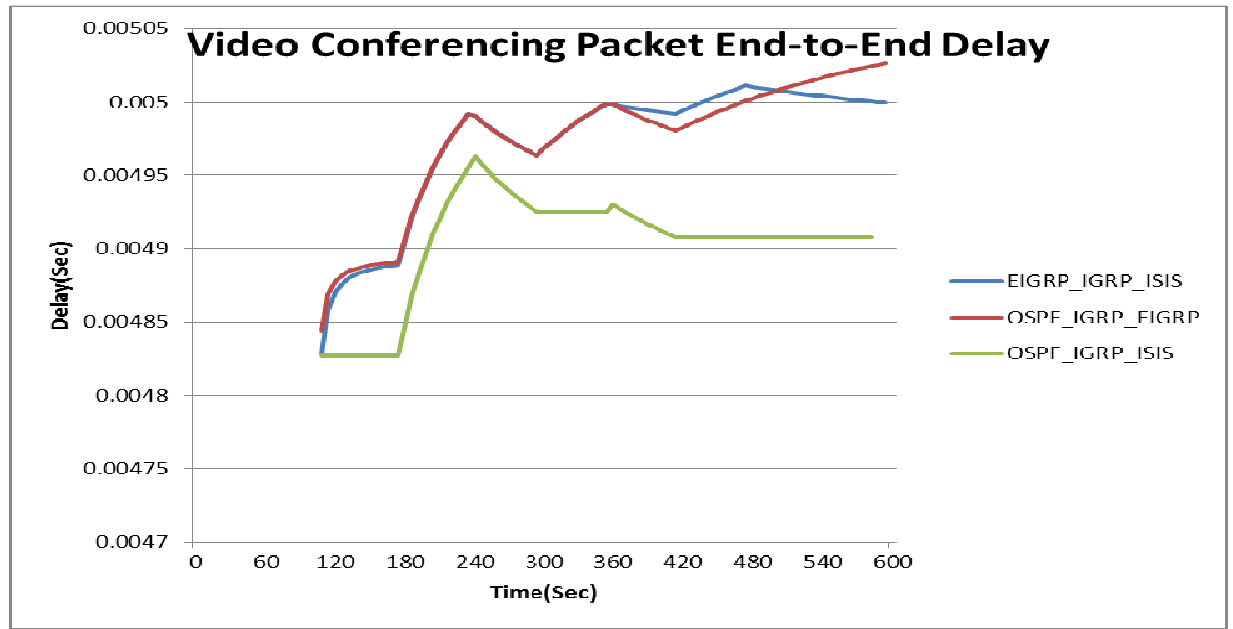

Figure 8. The video conferencing packet end to end delay.

\subsection{Voice Jitter}

The OSPF_IGRP_EIGRP scenario is better voice jitter from among the two other scenarios as seen in Figure 9, where a jitter is a variation in delay time of received packets.

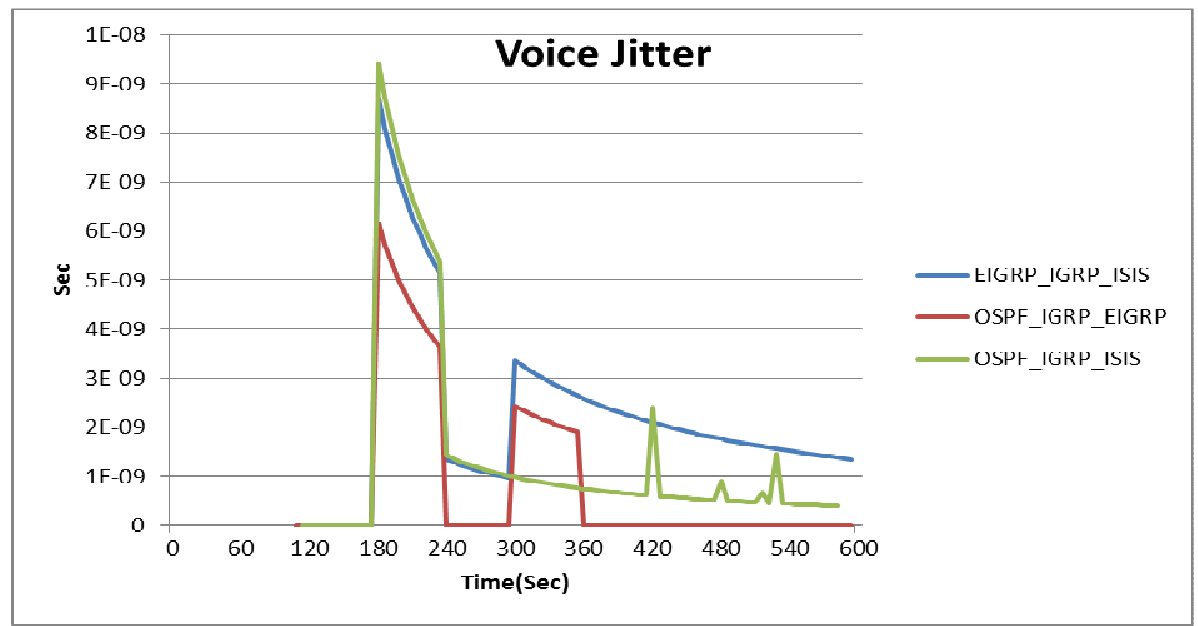

Figure 9. The voice jitter.

\subsection{Voice Packet Delay Variation}

Figure10 shows the OSPF_IGRP_ISIS scenario is better slightly than the two other scenarios in terms of the voice packet delay variation. We notice from Figure 10 that the delay difference between the values in the three scenarios is around $0.1 \mathrm{msec}$ at the beginning thereafter it goes to zero. 
International Journal of Computer Networks \& Communications (IJCNC) Vol.9, No.2, March 2017

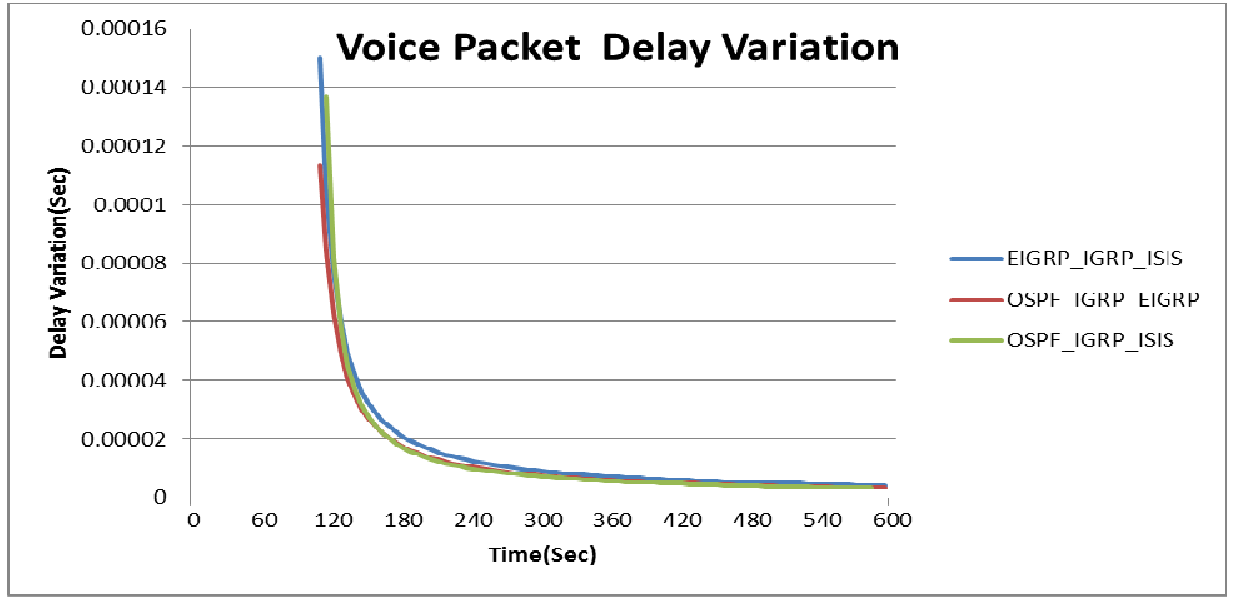

Figure 10. The voice packet delay variation.

\subsection{Voice Packet End to End Delay}

The OSPF_IGRP_ISIS scenario outperforms the two other scenarios in terms of the voice packet end to end delay as shown in Figure 11 therefore it is faster for sending a packet from source to destination over the network. We can see from Figure 9 to Figure 11 that the OSPF_IGRP_EIGRP scenario is better slightly than the OSPF_IGRP_ISIS scenario for voice service. Therefore, The OSPF_IGRP_ISIS scenario fits the real time applications such as voice and video conferencing.

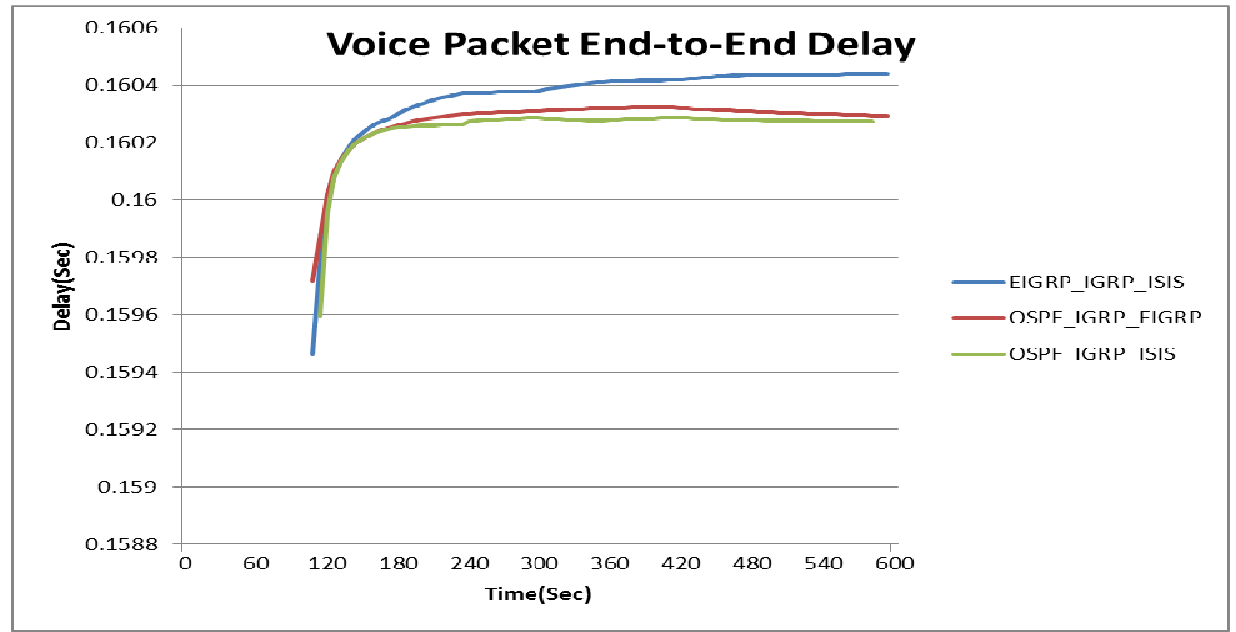

Figure 11. The voice packet end to end delay.

\subsection{FTP Download Response Time}

The response time of The EIGRP_IGRP_ISIS is the best performance than the two other scenarios as shown in Figure 12 since it is the fastest one for the FTP downloading service. 
International Journal of Computer Networks \& Communications (IJCNC) Vol.9, No.2, March 2017

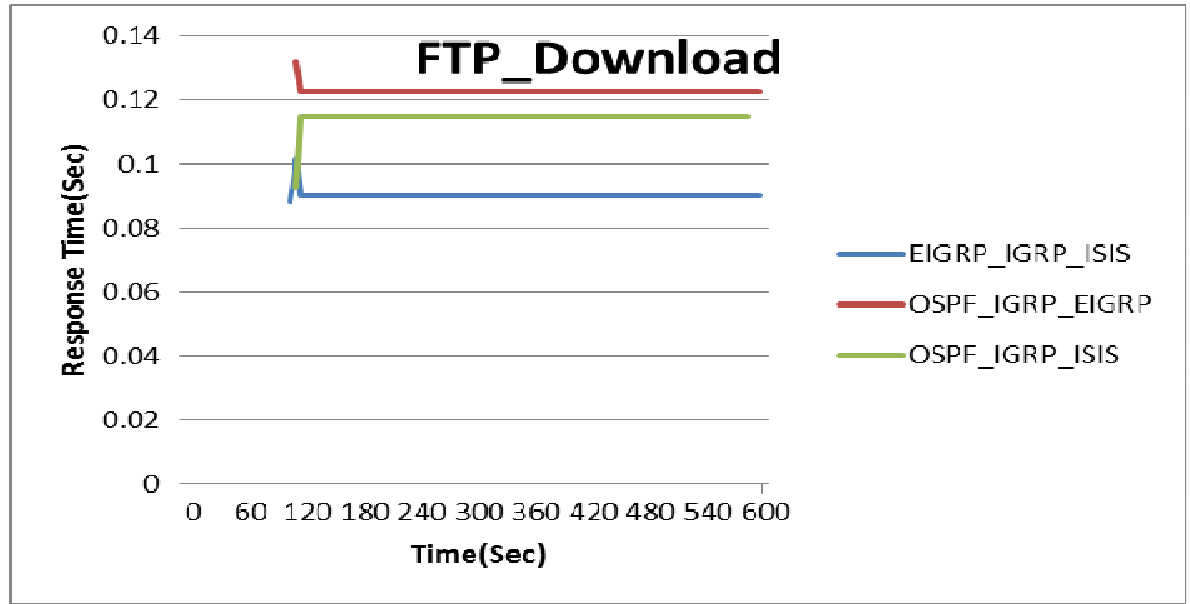

Figure 12. The FTP download response time.

\subsection{FTP Upload Response Time}

We can see from Figure 13 that the OSPF_IGRP_EIGRP scenario is faster the response time for the FTP uploading service before failure or recovery in the links are occurred whereas after failure or recovery occurred, it becomes higher slightly than the OSPF_IGRP_ISIS scenario. Therefore the OSPF_IGRP_EIGRP scenario has better slightly performance in terms of FTP uploading service. We can notice from Figure 12 and Figure 13 that the OSPF_IGRP_ISIS scenario fits FTP service in case of upload and download files are needed in the network.

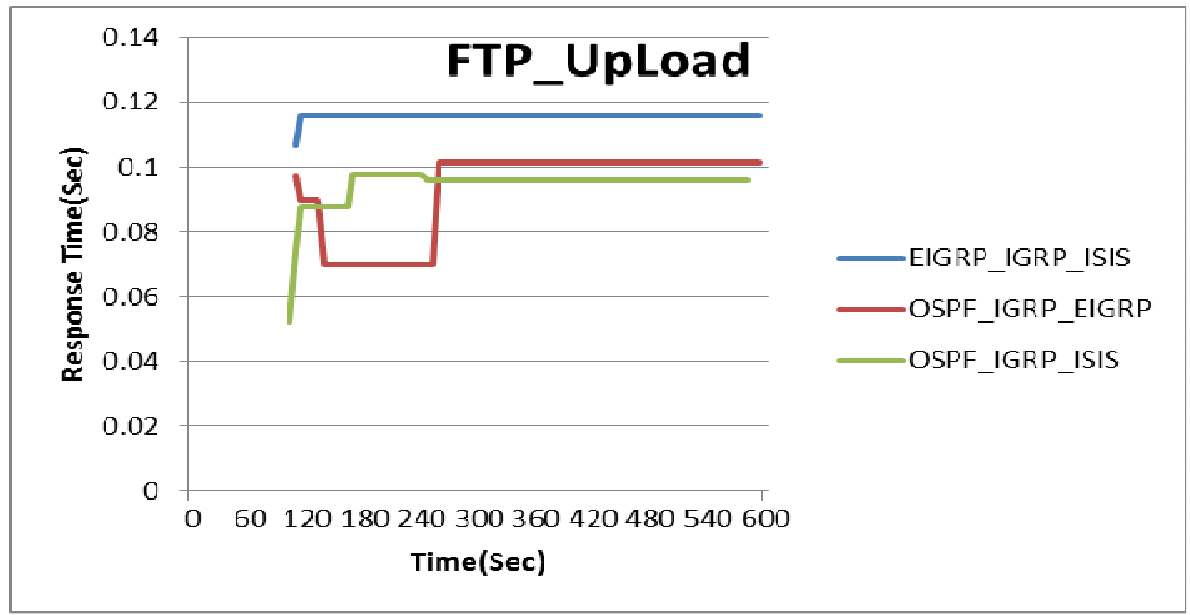

Figure 13. The FTP upload response time.

Finally, we present a quantitative comparison among the three proposed scenarios in terms of performance parameters in Table 2, where Table 2 shows the mean percentage performance value for each scenario in terms of convergence duration time, queuing delay, throughput, voice jitter, voice and video conferencing packet delay variations, voice and video conferencing packet end to end delays, FTP upload response time, and FTP download response time thereafter we rank each scenario into best, moderate, or worst according to its performance evaluation then we present the ranked results for the proposed scenarios in Table 3. We can notice from Table 2 and Table 3 that the OSPF_IGRP_ISIS scenario fits voice and video applications, on the other hand, the EIGRP_IGRP_ISIS scenario is a suitable for FTP download service, and in contrast, the OSPF_IGRP_EIGRP scenario is an appropriate for FTP upload service. We look deeply to the 
International Journal of Computer Networks \& Communications (IJCNC) Vol.9, No.2, March 2017 percentages in Table 2 in order to make a decision about the best proposed scenario in this paper therefore the OSPF_IGRP_ISIS is a suitable for FTP and real application services.

Table 2. The performance parameters comparisons among the proposed scenarios in terms of the percentage of mean value.

\begin{tabular}{|l|l|l|l|}
\hline $\begin{array}{l}\text { Performance Para. } \\
\text { (Mean) / Prop. Scenario }\end{array}$ & EIGRP_IGRP_ISIS & OSPF_IGRP_EIGRP & $\begin{array}{l}\text { OSPF_IGRP } \\
\text { _ISIS }\end{array}$ \\
\hline Convergence time(sec) & $100.00 \%$ & $53.89 \%$ & $54.38 \%$ \\
\hline Queuing delay(sec) & $64.36 \%$ & $77.29 \%$ & $100.00 \%$ \\
\hline Throughput(bits/sec) & $100.00 \%$ & $88.62 \%$ & $62.62 \%$ \\
\hline $\begin{array}{l}\text { Video conf. packet delay } \\
\text { variation(sec) }\end{array}$ & $100.00 \%$ & $63.13 \%$ & $4.23 \%$ \\
\hline $\begin{array}{l}\text { Video conf. packet end to } \\
\text { end delay(sec) }\end{array}$ & $98.62 \%$ & $98.59 \%$ & $100.00 \%$ \\
\hline Voice jitter(sec) & $37.77 \%$ & $100.00 \%$ & $57.30 \%$ \\
\hline $\begin{array}{l}\text { Voice packet delay } \\
\text { variation(sec) }\end{array}$ & $80.68 \%$ & $98.88 \%$ & $100.00 \%$ \\
\hline $\begin{array}{l}\text { Voice packet end to end } \\
\text { delay(sec) }\end{array}$ & $99.93 \%$ & $99.99 \%$ & $100.00 \%$ \\
\hline $\begin{array}{l}\text { FTP download } \\
\text { response(sec) }\end{array}$ & $100.00 \%$ & $73.42 \%$ & $78.77 \%$ \\
\hline FTP upload response(sec) & $80.32 \%$ & $100.00 \%$ & $98.27 \%$ \\
\hline
\end{tabular}

\section{Conclusions}

The route redistribution is an important issue in a boundary router configuration for a giant network such as an enterprise or university network that is used multiple routing protocols. We have created the three scenarios with diverse routing protocols configuration on the same network. The first scenario is configured from EIGRP, IGRP, and IS-IS, the route redistribution among OSPF, IGRP and EIGRP that is configured in the second scenario, and the third scenario is the combination of OSPF, IGRP, and IS-IS. The simulation showed the performance of the EIGRP_IGRP_ISIS scenario that is better in terms of FTP download response time, video packet delay variation, throughput, and network convergence time as compared with the other scenarios in this paper. On the other hand, the performance of the OSPF_IGRP_ISIS scenario outperforms the two other scenarios in terms of voice packet delay variation, voice and video conferencing packet end to end delay, and queuing delay. In contrast, the OSPF_IGRP_EIGRP scenario is better than the others in terms of FTP upload response time, and voice jitter. We notice from Table 3 that the OSPF_IGRP_ISIS scenario has strengths and slight weaknesses in terms of the performance parameters in our simulation. Therefore, we can conclude that the OSPF_IGRP_ISIS scenario withstands the links fluctuation between failure and recovery in the network; therefore it is a suitable for FTP service, and real time applications.

In the future work, we will simulate the route redistribution among three routing protocols in wireless network. 
International Journal of Computer Networks \& Communications (IJCNC) Vol.9, No.2, March 2017

Table 3. The performance parameters comparisons among the proposed scenarios.

\begin{tabular}{|l|l|l|l|}
\hline $\begin{array}{l}\text { Performance Para. } \\
\text { /Prop. Scenarios }\end{array}$ & EIGRP_IGRP_ISIS & OSPF_IGRP_EIGRP & OSPF_IGRP_ISIS \\
\hline Convergence time & Best & Worst & Moderate \\
\hline Queuing delay & Worst & Moderate & Best \\
\hline Throughput & Best & Moderate & Worst \\
\hline $\begin{array}{l}\text { Video Con. packet } \\
\text { delay variation }\end{array}$ & Best & Woderate & Worst \\
\hline $\begin{array}{l}\text { Video con. packet end } \\
\text { to end delay }\end{array}$ & Moderate & Best & Best \\
\hline Voice jitter & Worst & Moderate & Moderate \\
\hline $\begin{array}{l}\text { Voice packet delay } \\
\text { variation }\end{array}$ & Worst & Moderate & Best \\
\hline $\begin{array}{l}\text { Voice packet end to } \\
\text { end delay }\end{array}$ & Worst & Worst & Best \\
\hline $\begin{array}{l}\text { FTP download } \\
\text { response }\end{array}$ & Best & Best & Moderate \\
\hline FTP upload response & Worst & & Moderate \\
\hline
\end{tabular}

\section{REFERENCES}

[1] G. Malkin, (Nov. 1998), "RIP version 2,” RFC 2453.

[2] Cisco, (Aug. 2005), " An Introduction to IGRP”

[3] Cisco. (Jun. 2016). "Enhanced Interior Gateway Routing Protocol".

[4] ParkHurst William R (1998) : "Cisco Router OSPF : Design and Implementation Guide Cisco Technical Expert”, McGraw-Hill Professional.

[5] J. T. Moy, (Apr. 1998), “OSPF version 2," RFC 2328.

[6] Jose, San, (2006) . "Cisco IOS IP Configuration Guide”. USA : Cisco System, Inc. CA 95134-1706.

[7] D. Oran, (Feb. 1990 ), "OSI IS-IS intra-domain routing protocol," RFC 1142.

[8] F. Le, G. G. Xie, and H. Zhang, (2007), "Understanding route redistribution”, In Proc. International Conference on Network Protocols.

[9] Xin Sun, Sanjay G. Rao, Geoffery G. Xie, (Dec. 2012),"Modeling Complexity of Enterprise Routing Design", Proceedings of the 8th international conference on Emerging networking experiments and technologies, pp. 85-96, Nice, France, December 10 - 13, 2012

[10] D. Maltz, G. Xie, J. Zhan, H. Zhang, G. Hjalmtysson, and A. Greenberg, (2004), "Routing design in operational networks: A look from the inside", In Proc. ACM SIGCOMM, 2004.

[11] Cisco, (Mar, 2012), Redistributing Routing Protocols.

[12] Cisco, (Aug. 2005), "OSPF Design Guide".

[13] Cisco, (2002), "Introduction to Intermediate System-to-Intermediate System Protocol".

[14] S. Farhangi, A. Rostami and S. Golmohammadi, (2012),"Performance Comparison of Mixed Protocols Based on EIGRP, IS-IS and OSPF for Real-time Applications", Vol. 12 ,Issue 11, pp. 15021508,Middle-East Journal of Scientific Research.

[15] Golap Kanti Dey et al, (2015), "Performance Analysis and Redistribution among RIPv2, EIGRP \& OSPF Routing Protocol",1st International Conference on Computer \& Information Engineering (ICCIE 2015), At Rajshahi University of Engineering \& Technology(RUET), Rajshahi ,Bangladesh.

[16] Chairul Mukmin, Darius Antoni and Edi Surya Negara, ( February 2016), "Comparison Route Redistribution on Dynamic Routing Protocol (EIGRP into OSPF and EIGRP into IS-IS)", pp. 113119, The 5th ICIBA 2016, International Conference on Information Technology and Engineering Application Palembang-Indonesia, 19-20 February 2016.

[17] Mr.R. Jayaprakash and Ms.K. Saroja, (Jul. 2015),"RIP, OSPF, EIGRP Routing Protocols", International Journal of Research in Computer Application and Robotics, Vol. 3 Issue. 7, pp. 72-79.

[16] Fatima A. Hamza and Amr M. Mohamed, (Oct. 2011), "Performance comparison of two dynamic routing protocols: RIP and OSPF", Journal of Emerging Trends in Computing and Information Sciences, Vol. 2,No. 10,pp.509-513. 
International Journal of Computer Networks \& Communications (IJCNC) Vol.9, No.2, March 2017

[17] Vishal Nigam, Md. Samil Farouqui and Gunjan Gandhi, (Feb. 2014), "Enhanced Comparative Study of Networking Routing Protocols", International Journal of Advanced Research in Computer Science and Software Engineering, Vol. 4, Issue 4.

[18] N. Nazumudeen and C. Mahendran, (Feb. 2014), "Performance Analysis of Dynamic Routing Protocol Using Packet Tracer", International Journal of Innovative research in Science, Engineering and Technology, Vol. 3, Issue 1, p.570-574.

[19] Amrah Baba Ali and el al., (2016), "A Comparative Study of IGP and EGP Routing Protocols, Performance Evaluation along Load Balancing and Redundancy across Different AS", IMECS, March 16-18, 2016, Hong Kong.

[20] Archana C, (Mar. 2015), "Analysis of RIPv2, OSPF, EIGRP Configuration on router Using CISCO Packet tracer", Vol. 2, Issue 2, p. 215-222, IJESIT.

[21] Sandra Sendra and et al., (2010), "Study and Performance of Interior Gateway IP Routing Protocols", Vol. 2, No. 4, p. 88-117, Network Protocols and Algorithms.

[22] Abhishek Verma and Neha Bhardwaj, (2016), "A Review on Routing Information Protocol (RIP) and Open Shortest Path First (OSPF) Routing Protocol", Vol. 9, No. 4, pp. 161-170, International Journal of Future Generation Communication and Networking.

[23] V.Vetriselvan, Pravin R.Patil and M.Mahendran, (2014), "Survey on the RIP, OSPF, EIGRP Routing Protocols", Vol. 5(2),pp. 1058-1065,(IJCSIT) International Journal of Computer Science and Information Technologies.

[24] JASWINDER KUMAR, SAMIKSHA, SUSIL BHAGAT and KARANJIT KAUR, (Feb. 2015), "ROUTE REDISTRIBUTION BETWEEN EIGRP AND OSPF ROUTING PROTOCOL IN COMPUTER NETWORK USING GNS3 SOFWARE", Vol. 5, Issue 1, pp,27-34,International Journal of Computer Networking, Wireless and Mobile Communications (IJCNWMC),

[25] Chaganti B N Lakshmi and Dr. S.K.Mohan Rao, (Jan. - Mar. 2016) "Routing Layer Design issues and Protocols for Wired and Wireless Networks",Vol. 7, Issue 1,pp.9-13,International Journal of Computer Science And Technology,

[26] Vasudha and Dr.G.K.Jindal, (May 2011), "Investigations and Performance Evaluation of Dynamic Routing Protocol with New Proposed Protocol for WAN",Vol. 3 No. 5 , pp. 1970-1979, International Journal on Computer Science and Engineering (IJCSE).

[27] Mustafa Abdulkadhim, (March 2015), "Routing Protocols Convergence Activity and Protocols Related Traffic Simulation With Its Impact on the Network",Vol 5, Issue 3, pp. 40-43,International Journal of Computer Science Engineering and Technology( IJCSET).

[28] Priya Asher, (2015), "Comprehensive Analysis of Dynamic Routing Protocols in Computer Networks", Vol. 6, Issue 5, pp. 4450-4455, International Journal of Computer Science and Information Technologies (IJCSIT).

[29] Bhavna Rathi and Er. Farminder Singh, (Jul-Aug 2015),"Performance Analysis of Distance Vector and Link State Routing Protocols", Vol. 3, Issue 4, pp.23-32, International Journal of Computer Science Trends and Technology (IJCST).

[30] Paramjeet Singh Sandhu, Kamaljit Singh Bhatia, and Harsimrat Kaur, (2013), "Comparative Study of Various Router Protocols",pp. 13-15,International Conference on Innovations in Engineering and Technology (ICIET'2013) Dec. 25-26, 2013 Bangkok (Thailand).

[31] Neha Grang et al, (March-May, 2013), "Compare OSPF Routing Protocol with other Interior Gateway Routing Protocols",International Journal of Engineering, Business and Enterprise Applications, 4(2), pp. 166-170.

[32] Shubhi and Prashant Shukla, (October 2015), "Comparative Analysis of Distance Vector Routing \& Link State Protocols",Vol. 3, Issue 10,pp.9533-9539,International Journal of Innovative Research in Computer and Communication Engineering.

[33] Sonam, Rajan Vohra and Dr. Ravinder Singh Sawhney, (June 2014), "Dynamic Routing Protocols Analysis based on Dissimilar Number of Packets",Vol. 2, No. 4,pp.50-55,The SIJ Transactions on Computer Networks \& Communication Engineering (CNCE).

[34] Hamed Jelodar and Pouya Nikravesh, (March 2014), "ASSESSMENT OF RIP-V1 AND OSPF-V2 PROTOCOL WITH CONSIDERATION OF CONVERGENCE CRITERIA AND SENDING PROTOCOLS TRAFFIC", Vol. 8, No. 21,pp.1-4,Advances in Science and Technology Research Journal.

[35] D.VENKATAVARA PRASAD, SURESH JAGANATHAN and G.P SAIKALYAN, (2016), "Study and Analysis of Dynamic Routing Protocols in real time for Optimal Resource Utilization",vol. 1,pp.21-29,International Journal of Communications. 
International Journal of Computer Networks \& Communications (IJCNC) Vol.9, No.2, March 2017

[36] ARSALAN IQBAL and SAMEER LIAQAT ALI KHAN, (JANUARY 2015), "Performance Evaluation of Real Time Applications for RIP, OSPF and EIGRP for flapping links using OPNET Modeler",VOL. 3, NO. 1,pp.16-26,International Journal of Computer Networks and Communications Security.

[37] Jaswinder Kumar,Samiksha,Amandeep Kaur and Harsukhpreet singh, (Jan-Feb 2015), "Performance Analysis of RIPv2 protocol in Wired Network Using Cisco Packet Tracer",Vol 6, no.1,pp.16,Int.J.Computer Technology \& Applications,IJCTA.

[39] Haresh N. Patel, Prof.Rashmi Pandey, (Sept-Oct 2014), "Enhanced Analysis on Route Summarization and Route Redistribution with OSPF vs. EIGRP Protocols Using GNS-3 Simulation",Vol 5 (5), 16821689,Int.J.Computer Technology \& Applications(IJCTA).

[40] Mabubur Syed and Isaac Yerima Ambore, (November 2016), "PERFORMANCE EVALUATION OF OSPF AND RIP ON IPV4 \& IPV6 TECHNOLOGY USING G.711 CODEC", Vol.8, No.6,pp. 115,International Journal of Computer Networks \& Communications (IJCNC).

[41] Chandra Wijaya ,( 2011), "Performance Analysis of Dynamic Routing Protocol EIGRP and OSPF in IPv4 and IPv6 Network",ICI '11 Proceedings of the 2011 First International Conference on Informatics and Computational Intelligence ,Pages 355-360 December 12 - 14, 2011, IEEE Computer Society Washington, DC, USA @2011.

[43] D.Gurupandi , K.kumarra tamizh parithi, R.parthiban and M. gajendiran, (2015), "INTERCONNECTING ROUTING PROTOCOLS", 3rd International Conference on Advanced Research in Biology, Engineering, Science and Technology (ICARBEST'16), pp. 41-45.

\section{Authors}

Zeyad Mohmmad is working now as Assistant Professor at department of computer network, Al-Zaytoonah University of Jordan, Amman, Jordan. He received the $\mathrm{PhD}$ degree in Information Management/Cryptology and Network Security from National Chiao Tung University, HsinChu, Taiwan in 2010. He got his master degree in Computer Science from Amman Arab University for Graduate Studies, Amman , Jordan and he got his Bach. Degree in Computer Science from Mu'tah University His research interests include network protocols, network design, network security, wireless network, cryptography, cryptanalysis, authenticated key exchange and formal security models.

Dr. Ahmad Salameh Abusukhon is working now as an Associated Prof. at Al-Zaytoonah University of Jordan. He got his Ph.D in Computer Science from Sunderland University (United Kingdom, UK) in 2009. He got his master degree in Computer Science from the University of Jordan and he got his Bach. degree in Computer Science from Mu'tah University. Dr. Abusukhon is interested in Computer Networks, developing Data Encryption Protocols, Distributed Computing, and developing Search Engines. Dr. Abusukhon has published many papers in International Journals, and International Conferences.

Marzooq Ali Al-Maitah $\mathrm{He}$ is a lecturer (Master) of computer network at Department of Computer Network, Al-Zaytoonah University of Jordan, Amman, Jordan He received the Master degree in computer science from Jackson state university, USA. His research interests include network routing and switching, internet of things, and cloud computing.
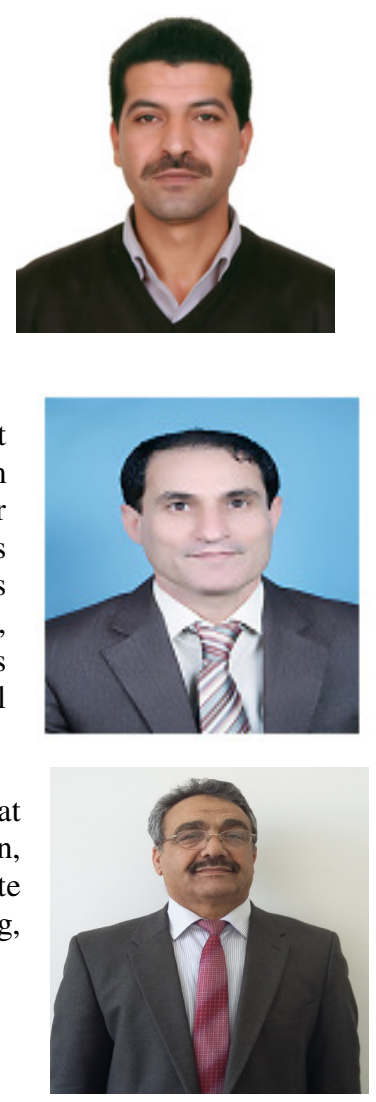